\title{
Lilijana Burcar
}

\section{Mladinske delovne akcije in železniške proge prve petletke: literarni zapisi in pomniki o izgradnji novega prostora in časa}

\begin{abstract}
Ključne besede: mladinske delovne akcije, Brčko-Banovići, Šamac-Sarajevo, literarni zapisi
\end{abstract}

DOI: $10.4312 /$ ars.13.2.184-202

Jugoslavija je med drugo svetovno vojno utrpela eno izmed največjih vojnih škod, in sicer 17 odstotkov vse škode zavezniških držav, če pri tem ne upoštevamo Poljske in Sovjetske zveze (Mrvič, 1983, n. pg.). Kljub temu so ji na pariški mednarodni konferenci za reparacije leta 1945 priznali le dva odstotka vseh zahtevkov (Matović, Damjanov, 1983, 164). Temu je sledila še gospodarska blokada z Zahoda, nato pa leta 1948 Informbiro in posledično gospodarska blokada z vzhodnega dela Evrope (Mrvič, 1983). Da bi se lahko socialistična Jugoslavija odcepila od polkolonialnega statusa in predvojne odvisnosti od Zahoda, sta bili nujni elektrifikacija ter izgradnja samozadostnega in razvejanega industrijskega bazena, pa tudi samooskrbnega kmetijstva. Socialistična Jugoslavija se je, da bi dosegla te cilje, morala nasloniti na lastne sile in notranje rezerve, še toliko bolj glede na novonastale težke geopolitične razmere. Mladina je zato na poziv USAO ${ }^{1}$ in $\mathrm{v}$ sodelovanju z ljudsko oblastjo prevzela novo vlogo v izgradnji dežele in novega družbeno-ekonomskega sistema: puške je zamenjala s krampi in lopatami, kar je postalo svojevrstno bojno orožje. Samo do zaključka prve petletke, tj. do leta 1952, je namreč več kot milijon udarniških parov mladih rok iz vseh republik in skorajda brez kakršnekoli mehanizacije skupaj zgradilo sedemdeset ključnih novih objektov (Jasnič v Pšeničny, 1976, 5) - od tega kar enajst železniških prog (Brčko-Banovići, Šamac-Sarajevo, Banjaluka-Doboj, Nikšić-Titograd, FočaKopač, Preserje-Borovnica, Sežana-Dutovlje, Goleš-Belačevac, Kučevo-Brodice, Gradačac-Modriča, Puračić-Doboj), šest avtocestnih tras (na primer Avtocesta bratstva in enotnosti, odsek Zagreb-Beograd) in pet hidrocentral (na primer Mavrovski sistem hidroelektrarn) (Pšeničny, 1976, 16; Stefanović idr., 1976, 32). Mladinske delovne akcije ( $\mathrm{v}$ nadaljevanju MDA) so bile ključnega pomena za izgradnjo in kasneje ohranitev neodvisnega gospodarsko-političnega sistema in $\mathrm{s}$ tem družbenega prostora, ki ga je predstavljala socialistična Jugoslavija.

1 Tj. Ujedinjeni savez antifašističke mladine Jugoslavije (USAOJ). 
Prostora zato ni mogoče obravnavati zgolj v ozkem geopolitičnem pomenu, marveč ga je treba najprej razumeti v sociološkem in političnem kontekstu. Da je takšno večplastno in strukturno prepleteno gledanje na prostor neobhodno, dokazuje prav fenomen MDA. Teh ne bi bilo mogoče vzpostaviti in še manj izvesti brez sočasne aktivizacije in organizacije celotne jugoslovanske družbe. Potreben je bil ogromen kolektivni napor, da bi MDA sploh stekle, tako v finančnem kot logističnem smislu. Glede na pičla finančna sredstva, ki jih je v prvih povojnih letih imela na voljo nova država, saj je bila večina gospodarstva uničena, je bilo za vzpostavitev MDA in njihovo preskrbo ter za samo izvedbo in zaključek gradbenih nalog treba aktivirati široko mrežo vzajemne pomoči. MDA so zato v tem pogledu v nekdanjem skupnem prostoru odigrale eno ključnih povezovalnih vlog. V prvem povojnem obdobju so bili poleg rezerv Narodne banke in denarnih zavodov ter mladinskega udarniškega dela odločilnega pomena še skladi za obnovo in razvoj dežele, v katere so vsi državljani in državljanke prispevali po svojih močeh (Mrvič, 1983). V ta namen so bile najprej vzpostavljene različne vrste drugih oblik organiziranega udarniškega dela, začenši $\mathrm{z}$ udarniškim delom po tovarnah in rudnikih na dnevni in tedenski osnovi ter $\mathrm{s}$ t. i. udarniškimi nedeljami. Dejstvo, da je na primer $» 150$ mladink in mladincev tovarne Trata v Škofji Loki organiziralo tri udarniške nedelje (3600 delovnih ur) ves zasluženi denar [pa] dal[o] v fond za obnovo«, je le droben ilustrativen kamenček v celotnem mozaiku te solidarnostne mreže (Mrvič, 1983, n. pg.). Podobno je bilo drugod po Jugoslaviji: v pripravah na gradnjo železniške proge Brčko-Banovići leta 1946 so svoje prispevale tudi druge delovne organizacije: tako je na primer delovni kolektiv tovarne Sartrid podaril 7.000 kosov izdelanega orodja, podobno so storile delavke in delavci drugih obratov v Velenju, Zagrebu in Sarajevu (Stefanović idr. , 1976, 24). Enak proces je stekel v pripravah na gradnjo druge proge, Šamac-Sarajevo, leta 1947, med drugim v okviru tekmovanja za 3. kongres Ljudske mladine Slovenije. Ni bilo nenavadno, da so delovni kolektivi poleg udarniških ur, za katere so plačilo že prispevali v sklad, tudi sami prevzeli skrb za materialno opremo mladink in mladincev, zlasti njihovih tovarniških mladinskih sekcij. Tako v katalogu Muzeja ljudske revolucije Slovenije beremo, da je »mladina Litografije Čemažar skupaj s sindikati prevzela obveznosti za določeno število mladincev, ki so odšli na progo, in za materialno pomoč, ki naj bi jo delavci s prostovoljnim delom prispevali za opremo brigad« (Mrvič, 1983, n. pg.). Da je lahko delo prvih mladinskih in kasneje tudi mnogih drugih delovnih akcij sploh steklo, je bil ključnega pomena tudi prispevek Jugoslovanske ljudske armade. Ta je namreč navadno prva pripravila teren in pri tem opravila najtežja dela. Na progi Brčko-Banovići je JLA najprej očistila gozdni teren, hkrati pa je s svojo tehniko, zlasti kompresorsko četo, bistveno prispevala k preboju na najtežjih odsekih, na primer predora Majevice, ter k tehničnemu usposabljanju mladih minerjev in kompresistov za nadaljnje samostojno strokovno delo (Matović, 
Damjanov, 1983, 165). Enako je bilo na progi Šamac-Sarajevo ter pri izgradnji Avtoceste bratstva in enotnosti. Tu so leta 1948 prve mladinske brigade na odseku Zagreb-Beograd že "pričakale inženirske, pehotne, intendantske, sanitetne in druge specializirane enote jugoslovanske armade, ki so med večmesečnimi pripravami postavile 250 kuhinj, 80 menz, 6 pekarn, 8 sanitetnih postaj, 3 bolnišnice itd.« (Matović, Damjanov, 1983, 167).

Prve in največje delovne akcije $\mathrm{v}$ obdobju prve petletke so bile namenjene izgradnji prometne in druge infrastrukturne mreže s poudarkom na gradnji novih železniških prog. Cilj je bilo odpreti in med seboj povezati ožji in širši geografski in porajajoči se nov gospodarski prostor, ki je bil poprej, za časa Kraljevine Jugoslavije, nerazvit in je hromil razvoj ostalih predelov dežele. Tako bi ne le omogočili (cenejši) pretok osnovnih energentov in surovin za izgradnjo in delovanje bazične industrije, temveč tudi pospešili izgradnjo in delovanje vse nadaljnje industrije ter razvoj mest in podeželja. Gradnja prve mladinske proge Brčko-Banovići je zato imela širši in racionalen cilj, s čimer je mladinsko udarniško delo prispevalo k medsebojni povezanosti celotnega jugoslovanskega gospodarskega območja, katerega najbogatejše surovinsko zaledje je bilo prav v BiH. Z izgradnjo proge BrčkoBanovići so bili postavljeni temelji za (samo)oskrbo nove industrije, ki bi Jugoslaviji zagotavljala gospodarsko samostojnost, $\mathrm{z}$ bogatimi in kvalitetnimi zalogami rjavega premoga iz poprej skorajda nedostopnega premogovniškega bazena Banovići-Seone. Hkrati so na ta način prevoz premoga povezali z železniškim križiščem v Vinkovcih in se tako izognili velikim pretovornim stroškom v Slavonskem Brodu (Kragović, 1983, 36). Po drugi strani so ta bogati rudni bazen z izgradnjo proge povsem na novo navezali tudi na rečna središča, kot je bilo Brčko, od koder so lahko premog kasneje dostavljali po Savi do HE v Obrenovcu in dalje vse do Beograda (Šmid, Štrumbl, 2014, 234). Izgradnja te proge je še povezala rudnik soli iz Tuzle z ostalim trgom in povečala izkop, hkrati pa omogočila razvoj vzhodne Bosne predvsem na račun koriščenja gozdnega bogastva za potrebe lesnopredelovalne industrije in na račun novovzpostavljene železniške oskrbne žile z živili iz vojvodinske žitnice (Kragović, 1983, 36). Izgradnja te proge je pomenila vzpostavitev novega gospodarskega trikotnika v ožjem medrepubliškem prostoru, ki je povezal industrijo Osijeka, Vojvodine in Beograda (Šmid, Štrumbl, 2014, 234), zato je ob odprtju proge 7. novembra $1946 \mathrm{iz}$ novoodprtega rudnika v Banovićih na pot krenila vlakovna kompozicija, napolnjena s premogom, iz Vojvodine $\mathrm{v}$ Banoviće pa vlak z žitom (Stefanović idr., 1976, 26). Podobni in geopolitično še večji cilji so zaznamovali tudi gradnjo druge mladinske proge Šamac-Sarajevo leta 1947. Namen je bil bogata nahajališča premoga in železove rude $\mathrm{v}$ dolini reke Bosne povezati $\mathrm{z}$ vso državo, $\mathrm{s}$ tem pa tudi BiH kot celoto $\mathrm{z}$ ostalimi predeli Jugoslavije, da bi tako zagotovili dovolj 
energentov in osnovnih surovin za vzpostavitev in delovanje industrijskega bazena tako v BiH, predvsem vzdolž doline reke Bosne, kot širom države (Kragović, 1983, 53). Z izgradnjo te druge mladinske proge leta 1947 so bili tako postavljeni tudi temelji za vzpostavitev vse bolj razvejane in modernizirane metalurške industrije v Zenici in Varešu, ki sta prerasla v osrednji središči tovrstne industrije $\mathrm{v}$ Jugoslaviji, pa tudi v Evropi (Stefanović idr., 1976, 32). Hkrati so bili postavljeni temelji ne le za ekstrakcijo, temveč tudi za predelavo cele vrste drugih surovin, na primer za potrebe industrije cementa ter lesnopredelovalne in prehranske industrije tako v $\mathrm{BiH}$ kot v širšem jugoslovanskem prostoru (Omladinska pruga, 1947, 15-16). Ta proga je namreč povezala vsa gozdna gospodarstva ob progi ter omogočila hitrejši vznik lesnopredelovalne in pohištvene industrije tako $\mathrm{v}$ dolini reke Bosne kot drugod po Jugoslaviji. Omogočila je tudi pretovor kmetijskih izdelkov in proizvodov zlasti svežega sadja (slive) za potrebe gospodinjstev, gostinstva in prehranske industrije po vsej Jugoslaviji, zlasti na sever in na jadransko obalo. Ta dobrina je bila namreč poprej popolnoma izgubljena, saj je bilo večino sadja zaradi nerazvite prometne mreže $\mathrm{v}$ najboljšem primeru mogoče konzervirati in uporabiti le s predelavo $\mathrm{v}$ alkoholne pijače (Krndija, 1948, 44). Proga Šamac-Sarajevo je ob kasnejši izgradnji odseka Sarajevo-Ploče nastopala kot osrednja prometna žila, ki je tekla skozi osrčje Jugoslavije od (njenega) severa proti jugu: kot del proge Šamac-Sarajevo-Ploče je namreč $\mathrm{BiH}$ povezala ne le s severnimi žitorodnimi področji Jugoslavije (Vojvodino in Banatom), temveč tudi z Jadranom, in je zato delovala kot strateško logistično ozadje za pristanišča v Splitu, Šibeniku, Gružu in Pločah (Krndija, 1948, 44). Podobno gospodarsko in geografsko povezovalno vlogo je kasneje imela mladinska proga Beograd-Bar, ki je bila zgrajena v letih 1970-1975. Enako velja za mladinsko progo Banjaluka-Doboj. Ta ni le povezala teh dveh, s surovinami bogatih predelov, marveč je bila grajena tudi kot vzporedna prometna žila z osrednjo železniško progo med Beogradom in Zagrebom. Izgradnja te železnice je prispevala k razbremenitvi osrednje železniške povezave med največjima mestoma v državi, hkrati pa na obeh povečala pretovor blaga iz vse Jugoslavije (Stefanović idr., 1976, 32). Avtocesta bratstva in enotnosti $(887 \mathrm{~km})$ - ki se je vila od Ljubljane, Zagreba, Beograda, Niša in Skopja ter se zaključila v Gevgeliji na makedonski meji z Grčijo - je delovala kot hrbtenica cestnega sistema na Balkanu. Pri tem pa ta mladinska cesta ni le povezovala vseh krajev Jugoslavije - od nje so se cepile vse pomembnejše poti proti žitnicam ter surovinskim območjem na severu in jugu dežele (Stefanović idr., 1976, 34) -, temveč tudi Srednjo in Zahodno Evropo z Balkanom in Bližnjim vzhodom (Mladina gradi, 1978, 38). Bila je namreč premišljeno umeščena tako, da je potekala po starih, a že zdavnaj opuščenih balkanskih cestnih trasah nekdanjega rimskega imperija (Vidmar, Dolenjskilist.si). 
Pomembno vlogo pri dokumentiranju in ohranjanju spomina na izgradnjo tega novega razvejanega železniškega prometnega ožilja, ki je odprlo in povezalo geografski in gospodarski prostor Jugoslavije, so v času MDA odigrali tudi literarni in pesniški zapisi takratnih jugoslovanskih umetnikov in umetnic. Ti so bili na MDA aktivni udeleženci in udeleženke ali pa so jih spremljali v okviru kulturno-umetniških in drugih prireditev, ki so potekale v naseljih mladinskih delovnih brigad in med prebivalstvom okoliških naselij. Danes je naključno ohranjenih le še nekaj razpršenih literarnih zapisov oziroma zbornikov, kajti večina jih je bila, kot kaže pregled katalogov Cobiss nekdanjih republik Jugoslavije, po letu 1991 izločena oziroma izvržena iz knjižnega gradiva. To pomeni veliko kulturno škodo in nepovratno uničenje zgodovinskega spomina, obenem pa tudi uničenje spomina na gradnjo in preoblikovanje geografskega in družbeno-ekonomskega prostora Jugoslavije, saj so zapisi imeli, kot dokazujem z izborom v nadaljevanju, tudi dokumentarno vlogo. Literarni in poetični izseki, ki jih predstavljam spodaj, so izbrani prav po tem dokumentarno-pričevalnem ključu: v njih avtorji beležijo ogromne človeške napore pri premagovanju geografsko razgibanega in težkega terena; pričajo o golorokem boju z naravo in proti njej ob skorajda nikakršni mehanizaciji. Kolosalnosti teh podvigov in specifičnih geografskih imen, povezanih z njimi, zato ni mogoče razumeti, ne da bi v razpravo vključila spremljajoče tehnične podatke o posameznih infrastrukturnih projektih oziroma njihovih najzahtevnejših odsekih. Prav ti dajejo literarnim zapisom osnovni kontekst. Predstavljeni prozni in poetični zapisi se nanašajo na premagovanje največjih geografskih ovir, ki so bile ogromen logistični in tehnični izziv. S tem izzivom se je bilo treba v prvi petletki spopasti zgolj z žuljavimi rokami, lopatami in samokolnicami. Tehnični podatki so neobhodni za razumevanje veličine projektov in delovnega zanosa MDA, ki jih metaforično zajemajo literarni zapiski takratnih angažiranih umetnikov in umetnic.

\section{Brčko-Banovići in pesniški utrinki Ivana Minattija}

Gradnja 92 km dolge proge Brčko-Banoviči se je začela 1. maja 1946 in končala 7. novembra, 22 dni pred rokom, ki ga je za svojo delovno obvezo sprejel III. kongres USAOJ. Pred tem je gradbeni odsek ministrstva za promet začrtal in izdelal elaborat trase v 20 dneh (Šmid, Štrumbl, 2014, 236) in skupaj z JLA izvedel prva pripravljalna dela, ki so se začela 1. aprila. Od 24. aprila dalje so vključevala tudi že prve predhodne mladinske brigade iz Srbije, Hrvaške, Makedonije in Kosova (Stefanović idr., 1976, 24). Proga Brčko-Banovići je bila kljub težavni konfiguraciji terena ob velikih naporih vseh udeleženih zgrajena v zgolj 190 delovnih dneh brez večje mehanizacije, tj. ob pomoči zgolj 14 kompresorjev, 21 mešalnikov betona, 13 drobilcev, 23 buldožerjev in 14 črpalk (Stefanović idr., 1976, 24). To je pomenilo, da jo je 62.280 mladink in mladincev iz vseh krajev Jugoslavije (od tega $2000 \mathrm{iz} \mathrm{tujine)} \mathrm{zgradilo} \mathrm{zgolj} \mathrm{s} \mathrm{pomočjo}$ 
samokolnic, krampov in lopat ter lastnih žuljev, pri čemer je bilo treba izkopati in vgraditi za vsaj »1.5 milijona kubičnih metrov zemlje in 140.000 kubičnih metrov kamenja« (Šmid, Štrumbl, 2014, 234), postaviti 300 nasipov in zgraditi 3 predore, 22 mostov (skupne dolžine $455 \mathrm{~m}$ ) ter 177 železniških in drugih podpornih zgradb, progo pa elektrificirati, torej opremiti z 2.100 električnimi in telefonskimi drogovi (Pšeničny, 1976, 14; Šmid, Štrumbl, 2014, 234). Najtežje in najzahtevnejše delovne akcije so potekale pri gradnji predora skozi Majevico in drugega večjega tunela Kiseljaka ter pri preboju skozi sotesko Orlovik. V Zborniku leposlovnih in likovnih del z mladinske proge tako najdemo skice in risbe Iveta Šubica, v katerih dokumentira delo mladih pri prepadnih Orlovih stenah. In medtem ko se Vladimir Lakovič v svojih skicah in risbah posveča izgradnji majeviškega tunela, Ivan Minatti (1924-2012) v pesmi Jutro na progi opisuje delo stotine parov mladih rok ob vznožju Majevice tik pred prebojem tunela. Od preboja Majevice in izgradnje $400 \mathrm{~m}$ dolgega tunela je bilo namreč odvisno, ali bo proga začela obratovati pravočasno, da bi lahko zagotovili tako potrebni premog za Vojvodino in Beograd ter nastajajoči industrijski bazen, s tem pa položili temelje prvi petletki. Minatti piše (1947, 8-9):

Trenutek še.

jutranji svit

je pljusknil čez goro

in potok v senci jelš

se je zasvetil kot srebro.

$\mathrm{Na}$ resastem strnišču

kaplje rose,

in kaplje na rumenem snopju žita:

in prav do tja, kjer bose

Bosanke žanjejo -

je višnjevost neba razlita.

Mi pa pojoč krepko v nov dan

smo krampe zasadili

in kot omotični

se v krhko prst zarili

$\mathrm{v}$ gigantskem ritmu tisočerih rok.

Kot pisan lok

se vije okrog ovinka

kipeči val teles. -

$\mathrm{Z}$ rdečo ruto krog vratu, mladinka

prepeva pesem nasmejanih lic,

in preko nas 
in njenih svetlih las

razsiplje sonce tisoče čudes.

In že se do pobočja Majevice,

kjer nad zelenjem sliv

moli v nebo prosojno

minaret črviv,

razločijo obrisi trase.

V zvenčanju krampov, batov in lopat nasip iz znoja, žuljev

in mladosti rase;

in vsi z mladostjo slutimo:

še malo

pa zdrvel bo preko polj, kjer se nasmiha mak, tovorni vlak,

in vsak prag,

vsak obok

bo pod kolesi pel zanosno himno naših mladih rok.

Poetično-estetska dimenzija Minattijeve pesmi se prepleta z njeno revolucionarno funkcijo. Zamahi srpov in ritem dela žanjic na polju, ožarjenem od jutranjega svita, se prelivajo in dopolnjujejo $\mathrm{z}$ ritmom dela tisočerih mladincev in mladink, ki v lesketajoči se svetlobi novega dne vihtijo krampe, da bi tej ritmično usklajeni skupnosti odraslih in mladih začrtali novo, drugačno traso življenja. Tako kot žanjejo sadove svojega preteklega dela roke žanjic danes, bodo žele roke mladih sadove svojega dela v svitu dneva, ki ga njihovo delo šele začrtuje. V Minattijevi pesmi se upanje v drugačen, boljši jutri, $\mathrm{v}$ katerega je vgrajeno tudi delo mladih rok, simbolično razodeva $\mathrm{v}$ nestrpnem pričakovanju preboja Majevice in prihoda vlakovne kompozicije, ki ji pot tlakuje zanosno in dobro organizirano delo mladih. To je delo, ki odpira nove, poprej neslutene poti in povezave, ter temeljno delo, ki postaja in ostaja trdno vgrajeno $\mathrm{v}$ nove tirnice in oboke novega, drugačnega sveta. V njem mladi ne le gradijo svojo prihodnost, ampak so že njen sestavni del. Smisel MDA namreč ni bila le fizična izgradnja objektov, temveč tudi tehnično in strokovno usposabljanje mladih, tako fantov kot deklet, za njihove bodoče poklice, da bi lahko tako ob pomoči tečajev sploh ali pa hitreje prešli na polkvalificirana in kvalificirana delovna mesta $\mathrm{v}$ industriji in kmetijstvu oziroma na industrijskih in infrastrukturnih objektih, ki so jih gradili. Tako je bilo samo pri gradnji proge Brčko-Banovići najprej opismenjenih nekaj več kot 5.000 mladih od skupaj 5.896 nepismenih; v okviru kulturno-prosvetnih dejavnosti pa je bilo med drugim poleg 1.158 stenskih časopisov organiziranih 3.177 bralnih skupin (Mihailović, 1983, 100), saj so brigade od samega začetka imele vedno na razpolago lastno knjižnico tudi z več tisoč enotami. To je veljalo tudi na tej prvi zvezni akciji, 
ki je imela na voljo več kot 80.000 knjig (ibid.). Na tej udarniški akciji je na primer več kot 4.000 mladih brigadirk in brigadirjev končalo strokovne in tehnične tečaje za buldožeriste, strokovne zidarje, praktične tehnike, pomočnike nadzornikov ter vodje mladih bralnih skupin in tečajev opismenjevanja (Kragović, 1983, 50), pa tudi pridobilo temelje za številne druge poklice. Tako je bilo tudi z minerji mladinci na Majevici. Ker je primanjkovalo strokovnega kadra, je vsaka brigada po nalogu Glavnega štaba prispevala po šest prostovoljcev, ki so končali tečaje za minersko usposabljanje in ob nadzoru starejših strokovnjakov prevzeli dela v tunelu. Oblikovana je bila minerska brigada, ki jo je sestavljalo 385 mladih minercev: ti so predor končno prebili 15 . avgusta 1947 (Stefanović idr., 1976, 25). Velika večina jih je kasneje na podlagi izkušenj in znanja, ki ga je pridobila prav na tem tečaju in poglobila med zimskimi pripravami na naslednji izziv, sodelovala pri gradnji druge mladinske proge, Šamac-Sarajevo.

\section{Šamac-Sarajevo: literarni zapisi}

Progo Šamac-Sarajevo, dolgo 243 km, je mladina začela graditi 1. aprila 1947 in jo dokončala 15. novembra 1947 v 280 udarniških delovnih dneh. Gradilo jo je 887 brigad oziroma 211.371 mladink in mladincev iz vseh republik in pokrajin (Pruga Šamac-Sarajevo, 1947, 75), od tega 6.000 mladih iz 42 drugih držav (Kragović, 1983, 54). Ta mladinska proga je bila nekajkrat daljša in zahtevnejša od prve: med drugim je bila zasnovana kot širokotirna proga prvega reda, z elementi torej, ki niso značilni za gorsko krajino, skozi katero je proga potekala, marveč za ravninske dele (Švabič, 1948, 32). V manj kot sedmih mesecih je bilo treba, kot kažejo podatki, izkopati in vgraditi več kot pet milijonov kubičnih metrov zemlje, in to ob pomoči le 108 buldožerjev, 90 kompresorjev, 27 avtomatskih nabijalnikov, 27 drobilcev in 12 traktorjev (Stefanović idr., 1976, 27). Pri tem so morali zgraditi 17 velikih mostov, dolgih od 90 do 180 metrov (od tega 14 preko Bosne in po enega preko Lašve, Spreče in Save), in 791 manjših mostov ter vanje vgraditi 23 tisoč kubičnih metrov betona, 9 predorov skupne dolžine 2425 metrov in 108 drugih objektov, večinoma novih železniških postaj - od tega štiri večje potniške in tovorne v Sarajevu, Zenici, Šarcu in Doboju (Omladinska pruga, 1947, 20; Švabič, 1948, 32; Stefanović idr., 1976, 27). In ne nazadnje, prestaviti je bilo treba tudi odsek $57 \mathrm{~km}$ dolge ozkotirne proge, ki je bila še v obratovanju, na novo progo pa položiti in vgraditi 335.000 pragov za 22 tisoč ton tračnic in nasuti več kot pol milijona kubičnih metrov drobirja (Stefanović idr., 1976, 27).

Progo in mladino, ki je delala na njej, je v času njene šestmesečne gradnje obiskalo več kot 600 tujih gostov, večinoma književnikov in drugih umetnikov, novinarjev in nekaj politikov (Kragović, 1983, 65). Obiskali pa so jo seveda tudi domači umetniki in umetnice. Kasnejši Nobelov nagrajenec Ivo Andrić (1892-1975) je v pozivu, 
naslovljenem Trasom omladinske pruge, marca 1947 domačo kulturniško srenjo pozval, naj podpre mladino in njene napore pri izgradnji skupnega prostora in novega družbeno-ekonomskega sistema, ki ne bo odvisen od eksploatacijskih interesov in posegov tujega kapitala $(1947,6)$ :

Mladino mora v tem delu spremljati dejavna simpatija, živo zanimanje in dejanska pomoč vseh državljanov Jugoslavije [...]. To še posebej velja za književnike [...], slikarje in glasbenike, igralce, znanstvenike in kulturne delavce nasploh. Veličino tega zgodovinskega podviga mora čutiti in doumeti vsak človek, to pa bo najbolje in najlažje doumel in čutil skozi umetniški ali znanstveni zapis, tj. skozi sliko in glasbo, skozi članek in pesem, skozi inteligentno reportažo. Zato je prva naloga naših pisateljev, umetnikov, znanstvenikov in publicistov, da delo, ki se te dni začenja na progi Šamac-Sarajevo, osvetlijo $\mathrm{z}$ različnih strani, pravilno ocenijo, pojasnijo in približajo razumevanju celotnega ljudstva. Poleg tega lahko s svojim darom in sposobnostmi veliko naredijo za izobrazbo in plemenito zabavo mladih graditeljev. S svojim zanimanjem in s sodelovanjem pri gradnji te zgodovinske proge pa se bodo tudi sami obogatili $\mathrm{z}$ znanjem in vtisi iz stvarnosti tega novega življenja naših narodov in bodo tako, s pomočjo pri gradnji proge, gradili in dopolnjevali tudi sami sebe kot ustvarjalci in umetniki. ${ }^{2}$

Progo in mladinske brigade je, nedvomno tudi zaradi Andrićevega lucidnega poziva, obiskalo 174 pisateljev, pesnikov, slikarjev in drugih umetnikov iz vseh jugoslovanskih republik (Jelisavetov, 1948, 107): nekateri v sklopu kulturnoumetniških prireditev, drugi kot graditelji na progi in/ali kot člani kulturno-prosvetnih odborov, katerih skrb je bila med drugim organizirati slikarske, literarne in druge kulturno-prosvetne krožke za udarniško mladino (ibid.). V svojih delih s proge in o njej dokumentirajo in izpričujejo bitko mladine $\mathrm{z}$ zahtevnim geografskim prostorom in časom ter za drugačen, gospodarsko samostojni in boljši jutri: torej za drugačen družbeno-ekonomski prostor, kjer bodo ljudje živeli od svojega dela. V tem smislu sta fizična bitka z geografskim prostorom in metafizična bitka za drugačen družbenoekonomski in življenjski prostor ne le prepletena, marveč strukturno neločljiva celota.

2 V izvirniku se ta citat glasi (ibid.): [Omladinu] [...] u tom radu [...] treba da prati aktivna simpatija, živ interes i stvarna pomoć svih građana Jugoslavije [...]. Ovo važi naročito za književnike [...] slikare i muzičare, glumce, ljude od nauke i kulturne radnike uopšte. Veličinu ovog istorijskog pothvata treba da oseti i shvati svak človek, a on će to najbolje i najlakše shvatiti i osetiti kroz umetnički ili naučni prikaz, tj. kroz sliku i muziku, kroz članak i pesmu, kroz inteligentnu reportažu. I stoga je prvi zadatak naših pisaca, umetnika, naučnika i publicista, da delo koje ovih dana počinje na pruzi Šamac-Sarajevo, osvetle sa raznih strana, pravilno ocene, objasne i primaknu ga shvatanju celog naroda. Osim toga, svojim darom i svojim sposobnostima, oni mogu mnogo učinit za obrazovanje i plemenitu razonodu mladih graditelja. A svojim interesovanjem i učešćem u gradnji ove istorijske pruge, oni će se i sami obogatiti sa znanjem i utiscima iz stvarnosti toga novog života naših naroda i tako će, pomažući izgradnjom pruge, uistinu izgrađivati i dopunjavati i sami sebe kao stvaraoci i umetnici. 
To je denimo razvidno iz reportažnega eseja hrvaškega pesnika Gustava Krkleca (1899-1977) Mladi graditelji, objavljenega v zborniku literarnih in pesniških del Društva hrvaških književnikov Na pruzi leta 1947:

Že iz prvih srečanj in pogovorov z graditelji Mladinske proge na pragu Nemile smo jasno prepoznali, da oni ne gradijo samo širokotirne železniške proge, temveč da polagajo širokotirne pragove našega skupnega življenja. Imelo me je, da bi vrgel svoj nahrbtnik iz džipa, kot da bi bilo v njem vse breme preteklosti, in da bi na dušek napisal pesem vere, poleta in dela ... $(1947,79)$.

Dlje ko potujemo, več je rdečih zastav, več udarniških brigad. Tovorni vlak iz Zenice pelje proti Šamcu, poln premoga in novih tirov za Mladinsko progo. Drugi tovorni vlak iz Šamca gre v Zenico, natovorjen z vrečami moke. Majhna podoba velike prihodnosti. Bosna pošilja blago svojih hribov severni nižini, nižina pa svoje obilje deli z Bosno. Zdi se mi, da bo enkrat za vselej utihnila tista starinska pesem Oj, Bosna, revica zakleta! $(1947,78)$.

Kdo bi lahko pomislil, da se Mladinska proga Šamac-Sarajevo gradi povsem enostavno $\mathrm{v}$ dolini ob reki, s kakšnim usekom, izpustom, mostičkom in predorom. Taki dobričini bi svetoval, da odrine do Nemile, se spusti do Lašve ali izstopi v Visokem. Takoj bi mu postalo jasno, da tu ne gre za enostavne, temveč za zelo zapletene in težke stvari in da se Mladinske proge, dolge 237 $\mathrm{km}$, ne gradi s poležavanjem. To je strahovita bitka proti naravi, proti stotini preprek, proti zemlji in kamnu, proti gorskim hudournikom in jarkom, proti vzpetinam in skalovju. Kalna Bosna stoka, ko se stoletja prebija po klancih in soteskah, mladi graditelji pa kopljejo za širokotirno železnico z nasmehom in pesmijo na ustih. In kar je najpomembneje, to novo, to široko železniško traso kopljejo neumorno, skoraj brez sape, brez odmora, da bi izpolnili častno zavezo, ki so jo dali sebi in ljudstvu, kot da so izkušeni mojstri, mizarji in tesarji, ne pa mladinci, skorajda otroci $(1947,82)$.

To so novi ljudje. Zavedajo se, da morajo varčevati s svojo energijo in je ne razsipavati, da je ta za skupnost, ne pa za osebnost, za dolgoročnost, ne pa za trenutek. Poleg tega se več kot dobro zavedajo, da je ta energija nujno potrebna prav v teh časih, $v$ teh dneh, ko je treba jasno in odločno pokazati, da je usoda naše dežele izključno v naših rokah in da smo zmožni sami upravljati in krmiliti našo ladjo $(1947,81){ }^{3}$

3 »Iz prvih susreta i razgovora s graditeljima Omladinske pruge na pragu Nemile, jasno smo razbrali, da oni ne grade samo željezničku prugu širokog kolosijeka, već da polažu pragove za široki kolosijek zajedničkog života. Došlo mi je da bacim svoju naprtnjaču iz džipa, kao da je u njoj sav teret jedne prošlosti, i da pijukom napišem novu pjesmu vjere, poleta i rada ...« $(1947,79)$.

"I što dalje putujemo, to više crvenih zastava, to više udarnih brigada. Teretni vlak iz Zenice putuje prema Šamcu, sav natovaren ugljenom i novim šinama za Omladinsku prugu. Drugi teretni vlak iz 
Ozkotirne in komajda obstoječe železniške proge je za časa aneksije Bosne in Hercegovine avstro-ogrski ter za časa Kraljevine Jugoslavije britanski, francoski in nemški kapital, ob lastniški soudeležbi domače buržoazije, nizkocenovno zgradil samo zato, da bi neposredno dostopal do nekaterih ključnih nahajališč lesnega in rudnega bogastva. Kapital in posledično država pri tem nista imela interesa, da bi naselja povezala med seboj, surovine pa so kapitalisti v skorajda nepredelani obliki po nizkih cenah prečrpavali za potrebe krepitve lastnega gospodarstva in razvoja ter rasti svojih vej industrije v zahodnih središčih, pri čemer v svoji surovinski periferiji niso vlagali v nobeno obliko industrije, med drugim tudi zato, ker bi ta industriji središča lahko postala konkurenčna. To je pomenilo, da je zahodni kapital, ki se je okoriščal s surovinami bosanskih rudnikov in gozdnih posestev, edini razpolagal z večino končnih izdelkov. Te je lahko posledično po nekajkrat višjih cenah prodajal nazaj območjem, od koder je prečrpaval surovine (Omladinska pruga, 1947, 6), zaradi česar je Kraljevina Jugoslavija uživala polkolonialni status. Odstranitev kolonialne ozkotirne proge in izgradnja širokotirne proge ponazarjata, tudi v zgornjih odlomkih Gustava Krkleca, simbolično preneseno, širokotirni izhod iz te bede in strukturne zaostalosti. Pomenita izhod iz tega podjarmljenja in predor v nov, drugačen, na novo osmišljen in gospodarsko neodvisen svet. Ta - in to je ključnega pomena - temelji na kolektivnem lastništvu proizvajalnih sredstev, $\mathrm{v}$ katerem zato človek $\mathrm{z}$ delom za skupnost $\mathrm{v}$ končni fazi dela tudi in predvsem zase, za svojo samostojnost in prosperiteto.

To je na svoj značilen, družbeno-kritičen in zgodovinsko-politično umeščen način izpostavil tudi Miroslav Krleža ob obisku prve mladinske proge, kjer za prispodobo te podjarmljenosti jemlje blato. Prekopavanje in boj z blatom na udarniški progi ob premagovanju useka na Kiseljaku je bilo resnično dejstvo, hkrati pa ima v Krleževem zapisu drug, simbolni pomen: jugoslovanske dežele kot nekdanje polkolonije, ki se $\mathrm{z}$ delom svojih mladih rok v okviru zastavljenega prvega petletnega gospodarskega

\footnotetext{
Šamca putuje u Zenicu, natovaren vrećama brašna. Mala slike velike budućnosti. Bosna šalje blago svojih brda sjevernoj ravnici, a ravnica svoje obilje dijeli s Bosnom. Sve mi se čini, da će doskora jednom za uvijek umuknuti ona starinska pjesma. Aoj Bosno, sirotice kleta!« $(1947,78)$.

"Netko može pomisliti, da se Omladinska pruga Šamac-Sarajevo gradi posve jednostavno, dolinom rijeke, s ponekim usjekom, propustom, mostićem i tunelom. Ja bi takvoj dobričini savjetovao, da krene do Nemile, da se spusti kod Lašve ili da se skine u Visokom. Odmah bi mu bilo jasno, da se tu ne radi o jednostavnim, nego naprotiv o vrlo zamršenim i teškim stvarima, i da se Omladinska pruga od 237 km ne gradi plandujući. To je strahovita bitka protiv prirode, protiv stotine prepreka, protiv zemlje i kamena, protiv gorskih bujica i jaruga, brda i hridina. Mutna Bosna stenje, probijajući se vjekovima kroz klance i klisure, a mladi graditelji probijaju široki kolosijek s osmjehom i pjesmom. I što je glavno, probijaju taj novi, taj široki kolosijek neumorno, skoro bez daha, bez predaha, da bi izvršili časno obavezu, koju su dali sebi i narodu, kao da su neki iskusni majstori, neki drveni neimari, a ne omladinci, gotovo djeca« $(1947,82)$.

"Novi su to ljudi. Oni su svijesni, da je njihova energija za štednju, a ne za rasipanje, za zajednicu, a ne za ličnost, za trajnost, a ne za trenutak. Oni su osim toga, i te kako svijesni, da je ta energija neophodno potrebna upravo u ovim vremenima, u ovim danima, kad valja jasno i odlučno pokazati, da je sudbina naše zemlje isključivo u našim rukama, i da smo u stanju sami upravljati kormilom svoga broda« $(1947,81)$.
} 
plana industrializacije in elektrifikacije države bojujejo za njeno gospodarsko neodvisnost od velikih sil in skupaj z njeno socialistično ureditvijo za preboj skozi blato izkoriščanja domačih in tujih kapitalistov. Krleža v svojem dnevniškem zapisu Izlet na mladinsko progo Brčko-Banovići (1952) tako značilno zapiše (cit. v: Kragović, 1983, 50, naš poševni tisk):

Proga kot tehnično delo: gore s soteskami, s kamnitim terenom, z vodami, z zemljo, z dežjem, s hudourniki, s koncem in s srednjim vekom. Pri Kiseljaku - boj z blatom. Samo v Galiciji med Strijem, Rožnjtovim in Kolomejo leta 1916 med ofenzivo generala Brusilova sem videl tolikšno količino blata kot pri Kiseljaku.

Blato-čorba, v kateri so se skuhale cele serije krvavih političnih kombinacij in bitk. Blato-driska zaradi strahovitih zgodovinskih zmed, ko zarjove zver $\mathrm{v}$ človeku in ko se drobovje skrči v smrtnem strahu. Blato, elementarno, strašno, črno, balkansko, prablato predsodkov preteklosti in sramote. $\mathrm{V}$ tem gostem smradu, ki se lepi na težke vojaške škornje kot kadavrov turški med, kjer vsak človeški korak spremlja gniloba, »to blato kot takšno«, »blato po sebi«, razbrazdano s kolesnicami, buldožerji, železnimi tračnicami prav nad predorom Kiseljaka: nekaj sto mladincev je v gibanju. Vpitje, zven žage, odmev nakovala, brnenje motorjev, nad vsem pa parabola tunela pri Kiseljaku, dostojna peresa velikega umetnika, ki bi nad tem gostim peklenskim kakavom iz blata znal razpeti lok, lok jasnovidne domišljije, $v$ tem zgodovinskem trenutku edinega možnega izhoda iz blatnega groba naše bede in zaostalosti. Kiseljak s svojim slavolokom - predorom, s svojim betonskim podkovanjem, karbidovkami in vagončki, z gibanjem mase bosonogih dečkov in deklic, je vreden monumentalne pesnitve na platnu. To ni prva proga na svetu, je pa prva, ki so jo zgradili otroci in jo poklonili Titu, ki je prvi človek naše politike in ki se mu posreči prebiti predore skozi našo najmračnejšo srednjeveško preteklost.

Krleža spaja premagovanje $\mathrm{v}$ dežju razmočenega in spolzkega terena na trasi gradnje nove železniške proge Šamac-Sarajevo (tehnično gledano gradbišča, ki je zaradi neugodnih vremenskih razmer pogrezajoče se blato, kar je bilo najbolj izrazito prav pri gradnji tunela Kiseljak) s premagovanjem blata izkoriščanja, v katero so bili pod okriljem velikih zahodnoevropskih imperialističnih sil in nove delitve interesnih sfer po koncu prve svetovne vojne ponovno pahnjeni balkanski narodi. Utiranje poti iz tega ekonomskega in geopolitično zaznamovanega blata lahko temelji le na samozadostnosti in spremembi družbeno-ekonomskega reda, ki je pisan na kožo malega človeka. Za vzpostavitev takšnega reda in njegovo ohranitev je potrebna vizionarska politika tako navzven kot navznoter, ki so jo premogli stari revolucionarji s Titom na čelu. To je 
Jugoslavijo pri prebijanju predorov novega mračnega, tj. neoimperialističnega veka in blokovske delitve druge polovice 20. stoletja, kot nesluteno že napoveduje Krležev literarni utrinek, kasneje postavilo na čelo Gibanja neuvrščenih.

Eden največjih udarniških zalogajev na drugi mladinski progi Šamac-Sarajevo je bila poleg izgradnje 600-metrskega mosta na nemirni Savi in useka v sotesko Lašve - tu je bilo treba iz strmih sten izkopati 94 tisoč kubičnih metrov kamenja, v strugo mrzle in deroče reke Bosne pa zacementirati več kot tisoč metrov visoke podporne zidove (Stefanović idr., 1976, 26) - izgradnja predora Vranduk. To je bil kar 1528 metrov dolg predor, ki je meril povprečno osem metrov v širino, saj je bil daljnovidno grajen zato, da bi po njem nekega dne peljale tudi električne lokomotive (Stefanović idr., 1976, 29). Da bi ga lahko dobesedno vklesali v enega najtrših tipov skale, je bilo treba izkopati 60.000 kubičnih metrov kamenin ob porabljenih 40 tisoč tonah eksploziva (Stefanović idr., 1976, 29). Delo je bilo še toliko bolj naporno, saj sprva niso imeli kompresorjev in so morali v trd kamen vrtati z ročnim orodjem, enako pa je veljalo za minerce pri polaganju eksploziva. Osnovani sta bili dve minerski mladinski brigadi, Prva in Druga, ki sta se dela lotili vsaka s svoje strani predora: 12. marca na vhodni in 17. marca na izhodni strani (Pruga Šamac-Sarajevo, 1947, 30). Na čelu preboja je lahko zavoljo zahtevnosti in ozkosti terena na vsaki strani v vsaki izmeni delalo le šest brigadirjev minerjev (Stefanović idr., 1976, 29); prebijanje predora pa je ob skupnem delu nekaterih starih minerjev strokovnjakov, mladih minerjev tečajnikov in mladinskih brigad trajalo polnih, a še vedno rekordnih 232 delovnih dni (Pruga Šamac-Sarajevo, $1947,54)$. To epsko delo je zato dokumentarno zabeležilo in ovekovečilo marsikatero umetniško pero.

Pisatelj Dušan Roksandić (1922-2003) v dokumentarni pripovedi Kod Užičana Vranduk postavlja ob bok prav tako zahtevni točki na progi, preboju useka na reki Lašvi. Da bi lahko sploh začeli z gradnjo trase na tem delu proge, je bilo namreč treba opraviti kolosalno delo: prestaviti ozkotirno progo ob breg reke Bosne pod previsne stene doline, na vrhu useka pa najprej odstraniti gozd in več kot osem tisoč kubičnih metrov zemlje (Pruga Šamac-Sarajevo, 1947, 40). Da bi lahko izsekali težko dostopno in mestoma do 21 metrov visoko steno, so kompresisti $\mathrm{v}$ trdo in nedostopno steno vrtali tudi tako, da so ves čas viseli ob steni, privezani za drevesa na vrhu previsnih sten (Pruga Šamac-Sarajevo, 1947, 41). Šlo je za boj volje in elana človeške sile proti trdemu in nevoljnemu kamnu, kar Roksandić v svoji pripovedi dokumentira tako (1947, 160):

Obiskal sem Osmo užiško mladinsko brigado, ki je v tretji izmeni delala na useku Lašve. Lašva je poleg Vranduka najbolj popularno delovišče na celotni Progi. Ko pridejo tujci in novinarji na Progo, si ogledajo tunel Vranduk, obiščejo Lašvo in se vrnejo, prepričani, da so videli Progo.

Lašva se imenuje en del doline reke Bosne, v lokalnem narečju graditeljev 
Mladinske proge pa ta beseda označuje sam usek. To je trda stena, trda, kot da bi jo narava namerno ustvarila za preizkus mladim graditeljem. Mesece mladina skupaj z Drugo tehnično četo borcev Jugoslovanske armade juriša na ta kamen, ki prenese tudi jeklo, kot pravijo minerji. Zidarsko kladivo, s katerim obdelujejo ta kamen, izgine v osmih dneh. Od lepega simetričnega orodja ostane samo še brezoblična grudica železa. ${ }^{4}$

Podobna hitra obrabljivost delovnega orodja $\mathrm{v}$ spopadu $\mathrm{z}$ naravo, ne pa tudi delovnega poleta, je veljala tudi pri delih na Vranduku, saj je šlo za enak tip kamnine. Po 232 dneh udarniškega dela je bil Vranduk premagan, kar je obeležila tudi hrvaška pesnica Vesna Parun v Pjesmi Vrandučkih minera (1947, 141-143):

1.

Noč se hribovska spušča. Potemni se Nemila.

Nad Nemilo se dviga strma gora.

Pod Nemilo gora

V sivem škrilavcu se jama votli

Po njej padajo molčeči obrisi črnih gozdov.

[...]

Uho gore sluti bitko, ki se pripravlja

[...]

Planina se boji minerskih rok.

2.

Minerji gredo: tiha vest se širi.

Pišne veter, hribi zaškripajo,

Kdo so minerji? Majhni brigadirji,

Kmetje od pluga in pastirji od paše.

Trpki fantje, šibo bi lahko grizli

Vse saje jim s planinami padajo na prsi.

A svojo stroko obvladajo: oni so tečajniki.

Zdaj strah in trepet za divjo sotesko.

[...]

3.

Prepih sten vpije. Drobir se drobi.

Dva juriša stokata, dva rova zaletena.

4 »Posjetio sam Osmu užičku omladinsku brigadu, koja je u trećoj smjeni radila na usjeku Lašvi. Lašva je pored Vranduka najpopularnije radilište na cijeloj Pruzi. Kad stranci i novinari dolaze na Prugu, obiđu tunel Vranduk, posjete Lašvu i vraćaju se natrag s uvjerenjem da su vidjeli Prugu. Lašvom se zove jedan dio doline rijeke Bosne, a u lokalnom narječju Omladinske pruge ta riječ označava sam usjek. To je tvrda stijena, tvrda kao da ju je priroda stvorila za kušnju mladim graditeljima. Mjesecima omladina zajedno sa Drugom tehničkom četom boraca Jugoslavenske armije juriša na kamen, koji nosi čelik, kako kažu mineri. Zidarski čekić, obrađujući taj kamen, nestane za osam dana. Od lijepe pravilne alatke ostane samo mala bezoblična grudica željeza.« 
Raste prehod prepoten. Vstopi: tu poteka rokoborba,

Prva minerska, sedemkrat udarna!

[...]

April. Maj. Junij. Termometer se vzpenja.

Z zastavo prestižno se podnevi dičijo.

$\mathrm{V}$ žveplo in potres se gora namaka,

Eksplozija podira težke rekorde.

Vse globlje, vse gosteje frčijo črne razvaline

Skozi tunelsko temačno zadušljivo krsto.

Devetindvajsetega, končno, iz teme

Izvije se gromki:

Prebit je

Vranduk! ${ }^{5}$

Vesna Parun zaključuje, da je bil Vranduk premagan 29. junija 1947, vendar pregled zajetnega arhivskega materiala razkriva, da je bil Vranduk uradno prebit 28. junija 1947 ob 11.45 dopoldne s prebojem Prve in Druge mladinske minerske brigade (Stefanović idr., 1976, 29). 27. oktobra 1947 pa so bila na tem ključnem objektu proge ŠamacSarajevo dokončana vsa betonska in druga gradbena dela, vključno s polaganjem tirov (Pruga Šamac-Sarajevo, 1947, 54). Tako je bila zgrajena in 16. novembra 1947 odprta osrednja železniška prometna žila, ki je nase vezala ne le surovinsko bogata območja za potrebe tako republiške kot celotne jugoslovanske industrije, temveč je povezala tudi novonastajajoče jugoslovanske industrijske bazene in mesta. Skupaj s še preostalimi železniškimi, avtocestnimi in drugimi prometnimi novogradnjami, ki so jih v tem obdobju zgradile večinoma mladinske delovne brigade, je proga ŠamacSarajevo tvorila prometno hrbtenico nove industrijske krajine. Slednja je bila začrtana tako, da je temeljila na vzpostavitvi gospodarske samozadostnosti, s tem pa skrbi za razvoj in neodvisnost jugoslovanskega gospodarskega sistema, zagotavljajoč hkrati funkcionalno enovitost in surovinsko zaokroženost nove države. Literarni zapisi, pesmi in kratke zgodbe takratnih jugoslovanskih umetnic in umetnikov - ki so danes zavoljo revizionizma ali ideološko priučenega malomarnega odnosa do kulturne dediščine naše polpreteklosti skorajda v celoti izgubljeni -, so pri reportažnem in

5 »1. Noć se brdska spušta. Smrknu se Nemila. / Nad Nemilom gora ispriječena visi./Pod Nemilom gora/U surome škriljcu pećina se zbila; / Po njoj crnih šuma šutljivi obrisi. / . . / Sluti uho brda bitku što se sprema ... / ... / Minerskih ruku planina se boji. / 2. Mineri idu: plaha vijest se širi. / Fijuknu vjetar, brda zaškripaše. / Tko su mineri? Mali brigadiri, / seljaci s pluga i čobani s paše. // Opori momci, prut bi mogli gristi / Sva čađ planinama na prsa im pada. / Al struku znaju: oni su kursisti. / Klisuri divljoj strah i trepet sada. / 3. Urla propuh stijena. Survine se mrve. / Dva juriša stenju, dva rova sudarna. / Raste prohod znojan. Uđi: tu se rve, / Prva minerska, sedam put udarna! // /... / Travanj. Svibanj. Lipanj. Termometar skače. / Zastavom prestiža podnevi se gorde. / U sumpor i potres brdo se umače,/Eksplozija teške prolama rekorde. // Sve dublje, sve gušće pršte crne ruine / Kroz tunelski mračni zagušljivi sanduk. / Dvadeset devetog, napokon, iz tmine / Izvi se gromki: / Probijen je / Vranduk!« 
dokumentarnem vpisu teh prometnic v preoblikovano geografsko in družbeno krajino odigrali, kot je izpostavil že Ivo Andrić, eno ključnih vlog. Zato še danes delujejo kot oblika tega, kar bi lahko poimenovali umetniško-dokumentarni zapis in vpis nekega prostora ter ohranitev krajine njegovega spomina.

\section{Bibliografija}

Andrić, I., Trasom omladinske pruge, v: Pruga Šamac-Sarajevo: dar omladine Titu $i$ narodu, Zagreb 1947, str. 1-6.

Jelisavetov, O., Kulturno - prosvetno delo na progi, v: Mladinska proga ŠamacSarajevo: prevodi iz listov »Borba na omladinskoj pruzi« in »Omladina« (ur. Peršič, Z.), Ljubljana 1948, str. 100-107.

Kragović, M., Tako je bilo - horuk za domovino, v: MDA - Mladost naše dežele (ur. Živković, M.), Beograd 1983, str. 9-195.

Krklec, G., Mladi graditelji, v: Na pruzi. Zbornik radova književnika iz Hrvatske o pruzi Šamac-Sarajevo (ur. Matković, M.), Zagreb 1947, str. 75-86.

Krndija, D., Pomen mladinske proge za gospodarski razvoj Bosne in Hercegovine, v: Mladinska proga Šamac-Sarajevo: prevodi iz listov "Borba na omladinskoj pruzi« in »Omladina« (ur. Peršič, Z.), Ljubljana 1948, str. 38-46.

Matović, R., Damjanov, P., V graditeljski vrsti, v: MDA - mladost naše dežele (ur. Živković, M.), Beograd 1983, str. 161-194.

Mihailović, S., MDA in njihovo uresničevanje, v: MDA - Mladost naše dežele (ur. Živković, M.), Beograd 1983, str. 70-119.

Minatti, I., Jutro na progi, v: Brčko-Banovići: zbornik leposlovnih in likovnih del z mladinske proge (ur. Željeznov, D.), Ljubljana 1947, str. 8-9.

Mladina gradi: ob 20-letnici izgradnje ceste Ljubljana-Zagreb, Ljubljana 1978.

Mrvič, S., Mladinske delovne akcije: 1945-1948. Katalog razstave, Ljubljana 1983.

Omladinska pruga Šamac-Sarajevo, Beograd 1947.

Parun, V., Pjesma Vrandučkih minera, v: Na pruzi. Zbornik radova književnika iz Hrvatske o pruzi Šamac-Sarajevo (ur. Matković, M.), Zagreb 1947, str. 141-143.

Pšeničny, V., Tri desetletja mladinskih delovnih akcij, Ljubljana 1976.

Roksandič, D., Kot Užičana, v: Na pruzi. Zbornik radova književnika iz Hrvatske o pruzi Šamac-Sarajevo (ur. Matković, M.), Zagreb 1947, str. 159-164.

Stefanović, M. idr., 30 godina omladinskih akcija, Beograd 1976.

Šmid, G., Štrumbl, Ž., Slovenske delovne brigade na mladinski železniški progi BrčkoBanovići, Arhivi 37/1 (2014), str. 233-244. 
Švabič, M., Dve mladinski progi, v: Mladinska proga Šamac-Sarajevo: prevodi iz listov »Borba na omladinskoj pruzi« in »Omladina« (ur. Peršič, Z.), Ljubljana 1948, str. 29-38.

Vidmar, I., Strinjajo se - »kapo dol« brigadirjem, Dolenjskilist.si, 3. 4. 2008, https:// www.dolenjskilist.si/2008/04/03/2401/reportaze_in_zanimivosti/clanek/ Strinjajo_se_kapo_dol_brigadirjem/ [13.5. 2019].

\section{Zahvala}

Za pomoč pri prevodu relevantnih odlomkov iz hrvaščine $\mathrm{v}$ slovenščino se zahvaljujem Đurđi Strsoglavec. 


\section{Lilijana Burcar}

\section{Mladinske delovne akcije in železniške proge prve petletke: literarni zapisi in pomniki o izgradnji novega prostora in časa}

Ključne besede: mladinske delovne akcije, Brčko-Banovići, Šamac-Sarajevo, literarni zapisi

Mladinske delovne akcije so bile ključnega pomena za izgradnjo in ohranitev neodvisnega gospodarsko-političnega sistema in s tem družbenega prostora, kot ga je predstavljala socialistična Jugoslavija. V prvi petletki po drugi svetovni vojni je bila še zlasti pomembna izgradnja novih prometnih žil, ki bi novonastajajočemu industrijskemu bazenu Jugoslavije zagotovile dostop do poprej slabo izkoriščanih in večinoma le izvoženih surovinskih bogastev. Na teh mladinskih gradbiščih so delovali tudi jugoslovanski umetniki in umetnice, katerih literarni in drugi prispevki med drugim dokumentirajo potek izgradnje objektov in njihovih najtežjih udarniških trenutkov, predvsem na železniških progah Brčko-Banovići in Šamac-Sarajevo. Kot taki so svojevrsten (literarni in zgodovinski) dokument svojega časa in geopolitičnega prostora $\mathrm{v}$ nastajanju, ki je danes zavoljo historičnega revizionizma skorajda $\mathrm{v}$ celoti izgubljen in ohranjen le še v nekaterih fragmentih. 
Lilijana Burcar

\section{Youth Work Actions and the New Railways of the First Five-Year Plan: Literary Works on the Construction as Historical Records of Their Time and Place}

Keywords: youth work actions, railway Brčko-Banovići, Šamac-Sarajevo, literature

Youth work actions in socialist Yugoslavia played one of the key roles in the building of the self-sufficient industrial base and the maintenance of an independent socio-economic system that would be free of neo-colonial shock-and-awe economic interventions, coming primarily from the West. Of key importance was the building of a new and extensive railway (and road) network. In this way, natural resource sites, which in the former Kingdom of Yugoslavia were either badly accessible or exploited only for export, could be now opened up to meet the needs of rising industry across the country. Renowned literary and other artistic names of former Yugoslavia also rose to the occasion by producing, among other things, literary works and poems, in which they document the work on these construction sites and trace the major obstacles the youth and technical experts had to overcome in their race against time and fight against nature on a very difficult geographical terrain. As such, these literary pieces represent a unique historical document of their time, recording not only the changing of the landscape but also the making of a specific geopolitical locale. Due to historical revisionism, most of these literary documents have been lost, with only a few of these still remaining scattered around various libraries in the region. 